\title{
Method for rating power cables buried in surface troughs
}

\author{
P.L.Lewin, J.E.Theed, A.E.Davies and S.T.Larsen
}

\begin{abstract}
An alternative method is detailed by which the ambient temperature parameter as applied to the calculation of ratings of cables buried in surface trough installations can be determined. Improvement in the accuracy of cable rating calculations will allow greater utilisation of the cable asset and assist for example in the planning of system outages for maintenance work. The proposed model calculates the temperature at the cable burial depth based on measurements of solar radiation, windspeed and air temperature. The model is based on physical laws rather than empirical approaches that have been shown to be generally conservative in application. Results based on weather data monitored over a two-year period show that the ambient temperature of the soil at cable depth can be accurately determined and the model provides a significant improvement on existing methods.
\end{abstract}

\section{List of symbols}

\begin{tabular}{|c|c|}
\hline 4 & cross-sectional area of an element $\left(\mathrm{m}^{2}\right)$ \\
\hline$C_{v}$ & volumetric heat capacity $\left(\mathrm{JK}^{-1} \mathrm{~m}^{-3}\right)$ \\
\hline$C_{k}$ & thermal capacity of the $k$ th element $\left(\mathrm{JK}^{-1}\right)$ \\
\hline & soil depth (m) \\
\hline & cable burial depth (m) \\
\hline & solar radiation intensity $\left(\mathrm{Wm}^{-2}\right)$ \\
\hline$H_{c}$ & $\begin{array}{l}\text { solar radiation intensity in cloudless conditions } \\
\left(\mathrm{Wm}^{-2}\right)\end{array}$ \\
\hline \multicolumn{2}{|c|}{$\begin{array}{l}H_{\text {measured }} \begin{array}{l}\text { solar radiation measured using pyranometer } \\
\left(\mathrm{Wm}^{-2}\right)\end{array} \\
\end{array}$} \\
\hline & convective heat transfer coefficient $\left(\mathrm{WK}^{-1} \mathrm{~m}^{-2}\right)$ \\
\hline & cable rating $(\mathrm{A})$ \\
\hline & number of cable cores \\
\hline & total number of elements in model \\
\hline & convective heat flux ( $\mathrm{Wm}^{-}$ \\
\hline & volumetric internal heat generation $\left(\mathrm{Wm}^{-3}\right)$ \\
\hline$i, 1$ & net heat exchange at ground surface $\left(\mathrm{Wm}^{-2}\right)$ \\
\hline$L W$ & $\begin{array}{l}\text { longwave radiation heat balance at ground surface } \\
\left(\mathrm{Wm}^{-2}\right)\end{array}$ \\
\hline$l w w$ & $\begin{array}{l}\text { longwave radiation reaching Earths surface from } \\
\text { sky }\left(\mathrm{Wm}^{-2}\right)\end{array}$ \\
\hline & $\begin{array}{l}\text { contribution of solar radiation to net heat } \\
\text { exchange }\left(\mathrm{Wm}^{-2}\right)\end{array}$ \\
\hline$R_{T H}$ & $\begin{array}{l}\text { thermal resistance for given length of cable } \\
\left(\mathrm{KmW}^{-1}\right)\end{array}$ \\
\hline
\end{tabular}

(ㄷ) IEE, 1999

IEE Proceedings online no. 19990360

DOI: 10.1049/p-gtd:19990360

Paper first received 10th September 1998 and in revised form 15th February 1999

P.L.Lewin, J.E.Theed and A.E.Davies are with the Department of Electrical Engineering, University of Southampton, Southampton, Hampshire, SO17 1BJ, UK

S.T.Larsen is with the National Grid Company plc, Leatherhead, Surrey, KT22 7ST, UK
$R_{k} \quad$ thermal resistance of $k$ th element $\left(\mathrm{KW}^{-1 \cdot 1}\right)$

$T_{\text {air }}$ air temperature $\left({ }^{\circ} \mathrm{C}\right)$

$T_{g r}$ ground temperature $\left({ }^{\circ} \mathrm{C}\right)$

$r \quad$ electrical resistance per unit length $\left(\Omega \mathrm{m}^{-1}\right)$

$v \quad$ windspeed $\left(\mathrm{ms}^{-1}\right)$

$W_{d}$ dielectric loss per unit length $\left(\mathrm{Wm}^{-1}\right)$

$\alpha \quad$ angle of elevation of sun

$\beta \quad$ Boltzmann constant $\left(5.76 .10^{-8} \mathrm{Wm}^{-2} \mathrm{~K}^{-4}\right)$

$\Delta t \quad$ time interval (s)

$\Delta \theta$ maximum permissible temperature rise $(\mathrm{K})$

$X$ daily cloud cover factor

$\chi$ fraction of shortwave radiation reaching ground surface under clear sky

$\chi_{\text {. }}$ fraction of shortwave radiation penetrating the cloud cover

$\varepsilon_{e l}$ emissivity of the Earth's surface to longwave radiation

$\lambda_{1}$ ratio of sheath losses to main conductor losses

$\lambda_{2}$ ratio of armour losses to main conductor losses

$\Theta \quad$ mean ground temperature $\left({ }^{\circ} \mathrm{C}\right)$

$\theta_{a} \quad$ ambient soil temperature at cable depth $\left({ }^{\circ} \mathrm{C}\right)$

$\theta_{\text {air }}$ air temperature $\left({ }^{\circ} \mathrm{C}\right)$

$\theta_{g r}$ ground surface temperature $\left({ }^{\circ} \mathrm{C}\right)$

$\theta_{j, k} \quad$ temperature of $k$ th element after $j$ time steps $\left({ }^{\circ} \mathrm{C}\right)$

$\theta_{s} \quad$ cable surface temperature $\left({ }^{\circ} \mathrm{C}\right)$

$\rho$ soil thermal resistivity $\left(\mathrm{KmW}^{-1}\right)$

$\sigma$ solar radiation absorption coefficient

$\Psi_{T}$ total heat dissipation per unit length $\left(\mathrm{Wm}^{-1}\right)$

\section{Introduction}

The main design parameter that limits the bulk transmission of electrical power using a buried cable is the conductor temperature of the cable itself. For a power cable there is a maximum operating temperature which if exceeded would cause the insulation to age at an increased rate. The life expectancy of the insulation material decreases exponentially as the operating temperature increases. It is there- 
fore helpful to determine the temperature of buried cables with improved accuracy to enhance cable capability. The continued development of data acquisition and monitoring techniques means that future cable networks may include temperature sensors, allowing the instantaneous cable rating to be readily determined. However, the cost of instrumenting existing networks would prove prohibitive and therefore there is a need to develop accurate methods of calculating the cable rating.

The temperature of the cable conductor can be predicted from the cable load, the thermal resistance to ambient and the ambient temperature. Therefore the load at which the cable temperature exceeds the maximum operating temperature can be calculated. This load is the cable rating and most of the parameters involved in its determination are accurately known. However, for buried cables the thermal resistivity of the soil and the ground ambient temperature are significant variable parameters. These parameters vary on a daily and seasonal basis and are dependent on the soil type. It has been standard engineering practice to calculate the cable rating using worst-case parameter values, ensuring that even in the most adverse conditions the maximum operating temperature would not be exceeded. In some cases, the standard rating parameters are so conservative that there is significant under utilisation of the cable asset.

To study the effect of environmental parameters on the rating of cables buried in surface troughs, a short section of three-phase surface trough has been constructed with the thermal losses of the cable circuit being represented by heater tape wound around aluminium formers [1]. The trough is fully instrumented and an adjacent weather station provides meteorological data at regular intervals. The data obtained over an 18-month period has been used to verify a physical model developed by the authors that can determine the ambient soil temperature at cable depth. The ambient temperature determined by the model can then be used in conjunction with the load history of the circuit to calculate the cable temperature.

\section{Determination of ambient temperature at cable depth}

Cables installed in surface troughs are buried at depths of between $0.3 \mathrm{~m}$ and $0.6 \mathrm{~m}$ as compared with normal burial depths in excess of $1 \mathrm{~m}$. Consequently, cables in surface troughs are more susceptible to changes in ambient conditions. To allow the use of the method of images, most established rating methods utilise the assumption that the ground surface is isothermal. Such an approach is appropriate for cables that are not buried near to the earth surface. Obviously for cables buried in surface troughs there is a considerable temperature rise of the ground surface above the cables and heat transfer from the ground surface will depend on the temperature difference between surface and air and climatic factors such as windspeed and solar radiation.

The standard method for calculating the steady state rating of cables is to use IEC 287 [2] which states that the cable rating $I$ can be defined as

$$
\begin{aligned}
& I= \\
& \left\{\frac{\Delta \theta-W_{d}\left[\frac{1}{2} R_{T H 1}+n_{c}\left(R_{T H 2}+R_{T H 3}+R_{T H 4}\right)\right]}{r R_{T H 1}+n_{c} r\left(1+\lambda_{1}\right) R_{T H 2}+n_{c} r\left(1+\lambda_{1}+\lambda_{2}\right)\left(R_{T H 3}+R_{T H 4}\right)}\right\}^{\frac{1}{2}}
\end{aligned}
$$

where $\Delta \theta$ is the maximum permissible temperature rise for a cable having $n_{c}$ cores each with an electrical resistance of $r$ ohms per unit length. The dielectric losses per unit length are defined as $W d, \lambda_{1}$ is the ratio of sheath losses to main conductor losses and $\lambda_{2}$ is the ratio of armour losses to main conductor losses. $R_{T H 1}, R_{T H 2}, R_{T H 3}$ and $R_{T H 4}$ are the thermal resistances across the dielectric, between the sheath and armour, between the armour and the outside surface and between the outside surface and ambient for a unit length of cable. To account for the effect of solar radiation, windspeed and ambient soil temperature on the rating of a cable buried near to the earth's surface a quantitative expression has been derived from the results of electrical analogue investigations of a three-phase cable circuit [3]. The temperature of the cable surface $\theta_{s}$ over a defined time period is given by

$$
\theta_{s}=\Psi_{T} R_{T H 4}+\frac{0.33 \Psi_{T}}{v^{0.74} d_{c}^{0.2}}+\frac{0.29 H}{v^{0.89} d_{c}^{0.07}}+\theta_{a}
$$

where $\Psi_{T}$ is the total heat dissipation, $v$ is the windspeed measured at a height of ten metres, $H$ is the solar radiation intensity and $\theta_{\mathfrak{a}}$ is the ambient soil temperature at the cable burial depth $d_{c}$. Although there has been acceptance of this expression [4], it is limited in its possible application and is only valid for a narrow range of windspeed and solar radiation values. Consequently, in practice a set of standard parameter values can be applied to a rating algorithm to account for the effect of environmental conditions on the overall cable temperature. For England and Wales, this worst-case approach assumes that in summer the soil thermal resistivity is $1.2 \mathrm{kmW}^{-1}$ and the ambient temperature is $40^{\circ} \mathrm{C}$. Providing a suitable backfill is employed and the backfill has adequate thermal performance when dry, this approach will lead to conservative ratings.

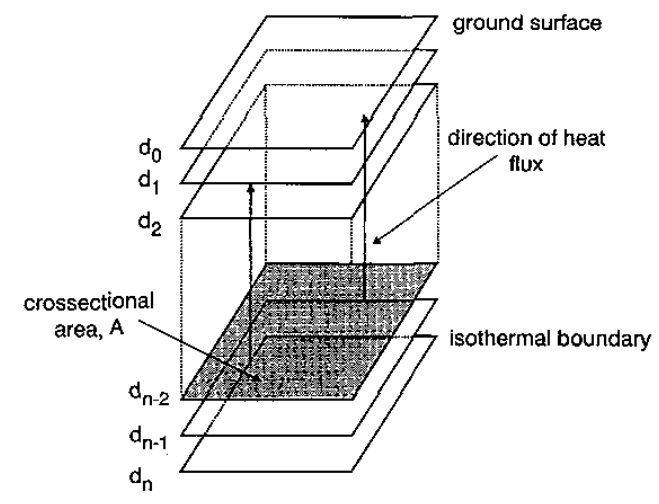

Fig. 1 Ground model

\subsection{Model based approach}

In the absence of additional sources of heat, the temperature gradient at any depth within the soil is perpendicular to the plane of the surface. The temperature of the ground at any depth can be obtained from a simplified version of Poisson's equation

$$
Q_{i}=C_{v} \frac{\partial \theta}{\partial t}-\frac{1}{\rho} \frac{\partial^{2} \theta}{\partial d^{2}}
$$

where $\theta$ is the temperature, $C_{v}$ is the volumetric heat capacity, $\rho$ is the thermal resistivity, $d$ is the depth and $Q_{i}$ is the internal heat generation. Generally internal heat generation is zero and through the use of a laminar geometry this equation can be solved. The ground is modelled as a series of $n$ horizontal elements each of cross-sectional area $A$ as shown in Fig. 1. This approach is analogous to an electrical $R C$ ladder network. The temperature of the $k$ th element can be determined every $\Delta t$ seconds, such that after $j$ time steps the temperature of the element is 


$$
\begin{aligned}
& \theta_{j, k}=\theta_{j-1, k} \\
&+\frac{\Delta t}{C_{k}}\left\{\frac{\theta_{j-1, k-1}-\theta_{j-1, k}}{R_{k-1}}+\frac{\theta_{j-1, k+1}-\theta_{j-1, k}}{R_{k}}\right\} \\
& 2 \leq k \leq n-1
\end{aligned}
$$

where $C_{k}$ is the thermal capacity of the $k$ th element, which can be defined as

$$
C_{k}=C_{v} A\left(d_{k}-d_{k-1}\right)
$$

Similarly $R_{k}$ is the thermal resistance of the $k$ th element and is

$$
R_{k}=\frac{\rho\left(d_{k}-d_{k-1}\right)}{A}
$$

At a certain depth, the soil is constantly at the mean ground temperature $\Theta$, irrespective of weather conditions or the time of year. To ensure reasonable performance the depth of the lower surface of the $n$th element needs to be sufficient so that it can be assumed to be at the mean ground temperature. In addition, the first element must account for the heat flux at the ground surface that is a function of known parameters. The temperature of the first and last elements can be defined as

$$
\begin{array}{ll}
\theta_{j, 1}=\theta_{j-1,1} & +\frac{\Delta t}{C_{0}}\left\{\frac{\theta_{j-1,2}-\theta_{j-1,1}}{R_{0}}+A q_{j, 1}\right\} \\
& \text { for } k=1 \\
\theta_{j, n}=\Theta \quad \text { for all } j, k=n
\end{array}
$$

where $q_{j, 1}$ is the net heat exchange at the ground surface.

\subsection{Heat exchange at ground surface}

The net heat exchange at the ground surface at the jth time step can be defined as

$$
q_{j, 1}=q_{s r_{j}}+q_{c_{j}}+q_{L W_{j}}
$$

where $q_{s r}$ is heating due to solar radiation, $q_{c}$ is the convective heat flux and $q_{L W}$ is the longwave radiation heat balance at the ground surface. The relative size of each component is seasonal [5].

2.2.1 Solar radiation: The average energy flux of solar radiation above the atmosphere at the mean distance of the earth from the sun is $1367 \mathrm{~W} / \mathrm{m}^{2}$ and due to the elliptical path of the earth's orbit this will vary over the year. The amount of radiant heat energy reaching the earth's surface will depend on the cloudiness of the sky and the distance through the atmosphere that the sun's rays travel. The solar radiation incident on the earth's surface on a clear day $H_{c}$ is defined as

$$
H_{c}=1367 \chi \sin \alpha
$$

where $\chi$ is the fraction of short wave radiation that reaches the ground under clear skies and $\alpha$ is the angle of elevation of the sun [6]. Some of the solar radiation will be reflected back from the ground, but a proportion will be absorbed, dependent on the solar radiation absorption coefficient $\sigma$ of the material on the earth's surface. The contribution of solar radiation to the overall heat transfer equation can be defined as

$$
q_{s r}=\sigma \chi_{c} \chi 1367 \sin \alpha
$$

where $\chi_{c}$ is the fraction of sunlight penetrating the cloud cover, such that a clear sky would have a value of 1.0. Using a pyranometer it is possible to measure solar radiation at ground level and given that both $\chi$ and $\alpha$ are known the clear sky value at each sample instant can be determined. If $m$ measurements are made over a day then the daily cloud cover factor $X$ can be defined as

$$
X=\frac{1}{m} \sum_{i=1}^{m} \frac{H_{\text {measured }_{i}}}{H_{c_{i}}}
$$

The value of $X$ is significant in determining the short wave radiation that reaches the ground and the long wave radiation heat balance (eqn. 2).

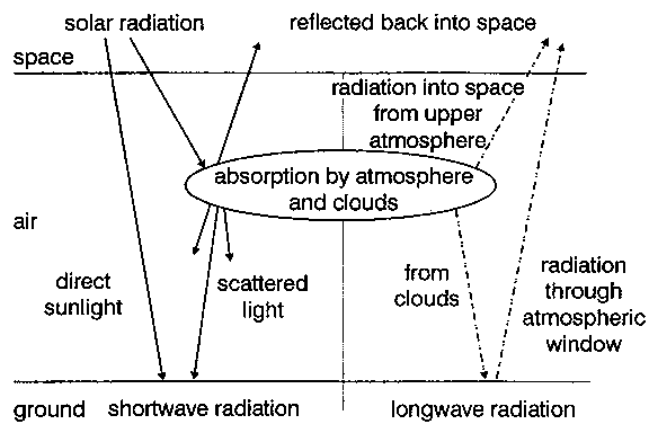

Fig.2 Radiative heat balance at ground surface

2.2.2 Convection: The convective heat flux from ground to air is equated to the difference between the ground and air temperatures multiplied by the convective heat transfer coefficient $h_{c}$, that is

$$
q_{c}=h_{c}\left(\theta_{g r}-\theta_{a i r}\right)
$$

This equation has been implemented so that the value of the convective heat flux for a given time step is determined using the present air temperature and the ground temperature calculated for the previous time step. It is difficult to determine the convective heat transfer coefficient, but an expression has been obtained from experimental data measured at Poona, India [7]

$$
h_{c}=6.0+4.6 v
$$

Eqn. 13 may lead to an overestimation of the heat transfer coefficient for conditions in the UK. It is hotter in India and the difference between ground and air temperatures are likely to be larger. However, sensitivity analysis has shown that this approach does not result in significant error within the overall calculation.

2.2.3 Longwave radiation: The Earth's surface emits longwave radiation such that

$$
q=\varepsilon_{e l} \beta T_{g r}^{4}
$$

where $\beta$ is the Boltzmann constant $\left(5.76 \times 10^{-8} \mathrm{Wm}^{-2} \mathrm{~K}^{-4}\right)$, $T_{g r}$ is the temperature of the ground surface in Kelvin and $\varepsilon_{e l}$ is the emissivity of the Earth's surface to longwave radiation that has an approximate value of unity. This radiation is readily absorbed by the atmosphere, causing atmospheric temperature rise, leading to reradiation. Some of the reradiated energy will be directed towards the ground. Based on international data, the average magnitude of longwave radiation reaching the Earth's surface from cloudless sky has been estimated as [8]

$$
q_{l w}=-170.9+1.195 \beta T_{\text {air }}^{4}
$$

Alternatively, measurements at Benson in Oxfordshire [9] have yielded an estimate of

$$
q_{l w}=-105.2+1.03 \beta T_{a i r}^{4}
$$

In cloudy conditions, eqns. 15 and 16 are not valid as cloud containing water droplets will act as a black body to longwave radiation, consequently for overcast skies

$$
q_{l w}=\beta T_{a i r}^{4}
$$


Given the climatic conditions of the UK it is necessary to obtain an expression representative of longwave heat flux in conditions of intermediate cloud cover. This is achieved by using the daily cloud cover factor (eqn. 11) as a weighting factor such that the longwave heat balance at the ground surface can be defined as

$$
\begin{aligned}
& q_{L W}=\beta\left(T_{a i r}^{4}-T_{g r}^{4}\right) \quad X<0.2 \\
& q_{L W}=\beta\left(T_{\text {air }}^{4}-T_{g r}^{4}\right) \\
& -\frac{X-0.2}{0.8}\left(170.9-0.195 \beta T_{\text {air }}^{4}\right) \\
& 0.2 \leq X \leq 1.0
\end{aligned}
$$

\section{Performance of ambient temperature model}

Temperature variation is greatest at the ground surface and around the cable. The temperature of the soil varies less as the depth increases and consequently the dimensions of the model were defined by dividing a distance equal to twice the cable burial depth into ten equal elements and then dividing the remaining distance to the depth at which the soil temperature is assumed constant into a further ten elements. Increasing the number of elements beyond 20 was found to have little net benefit at the expense of increased computation time.

The definition of initial conditions is also important, although experimentation has shown that the model will produce reasonable results within a few time steps even when the initial soil temperature conditions are poorly defined. Typical initial conditions are detailed in Table 1. Each element requires an initial temperature and this was defined using linear interpolation to define temperature by depth.

Table 1: Typical initial conditions

\begin{tabular}{lll}
\hline Parameter & Symbol & Value \\
\hline volumetric heat capacity & $C_{v}$ & $1.7 \mathrm{M} \mathrm{JK}^{-1} \mathrm{~m}^{-3}$ \\
cable burial depth & $d_{c}$ & $0.3 \mathrm{~m}$ \\
overall soil depth & $d_{n}$ & $7.0 \mathrm{~m}$ \\
number of elements & $n$ & 20 \\
time interval & $\Delta t$ & $1800 \mathrm{~s}$ \\
mean ground temperature & $\Theta$ & $12^{\circ} \mathrm{C}$ \\
ground surface temperature & $\theta_{g r}$ & $12^{\circ} \mathrm{C}$ \\
soil thermal resistivity & $\rho$ & $0.73 \mathrm{kmW}^{-1}$ \\
solar radiation absorption coefficient & $\sigma$ & 0.65 \\
\hline
\end{tabular}

The model was tested using locally logged weather measurements and obtained results compared to online soil temperature measurements made at a depth of $300 \mathrm{~mm}$. The weather data have been measured at half hourly intervals for over two years and the model has been tested using sampled air temperature, windspeed and solar radiation values. Calculated results (Figs. 3 and 4) are compared with the thermocouple temperature measurement made at the notional cable depth.

To be applicable to the rating of cables it is important that the obtained results can be applied over reasonable distances from the point of measurement. To further validate the model air temperature, solar radiation and windspeed data obtained at Drax power station, North Yorkshire were used to calculate the ambient soil temperature at depths of 0.3 and $1 \mathrm{~m}$ using a time interval of 24 hours. The model output has been compared with 9.00 a.m. temperature measurements over a period of two years from the nearest meteorological station (Figs. 5 and 6) which is 25 miles away at Rotherham. The output of the model is in very good agreement with the measured 9.00 a.m. data, given that factors such as local soil type, ground surface and altitude will affect soil temperature.

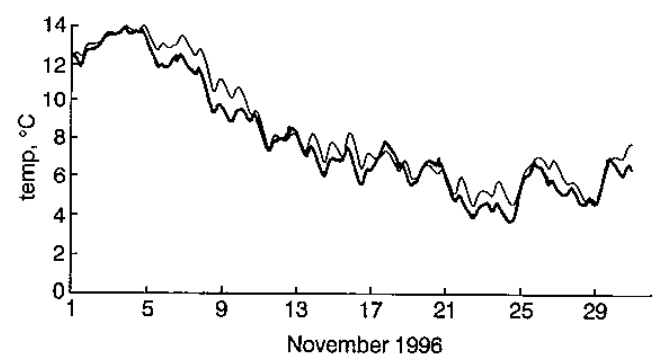

Fig.3 Comparison of model output and measured grotond temperature at $0.3 \mathrm{~m}$ depth during winter in Southampton, Hampshire predicted

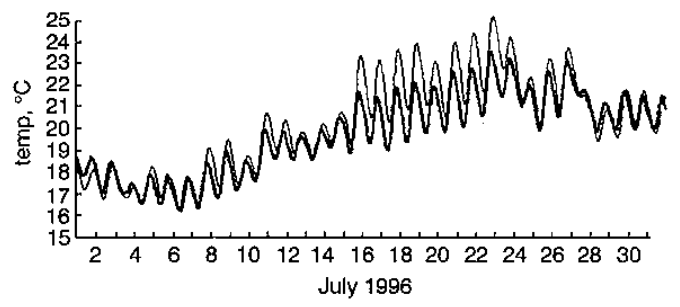

Fig.4 Comparison of model output and measured ground temperature at $0.3 m$ depth during summer in Southampton, Hampshire predicted

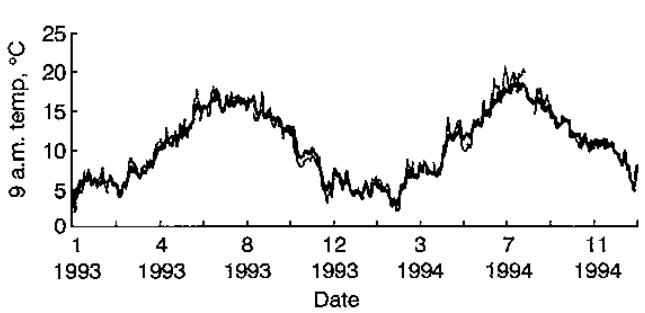

Fig. 5 Comparison of 9.00 a.m. measured temperature at $0.3 \mathrm{~m}$ depth with predicted temperature based on weather data measured 25 miles distant over period of two years

- predicted, Drax power station

- measured, Rotherham met. station

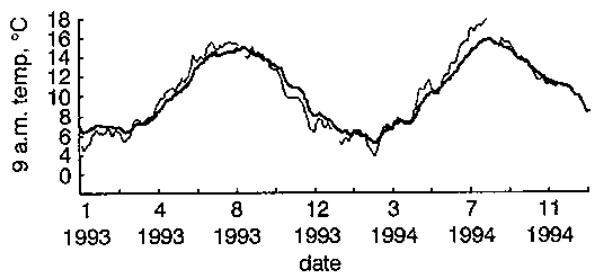

Fig.6 Comparison of 9,00 a.m. measured temperature at $1 m$ depth with predicted temperature based on weather data measured 25 miles distant over period

of two years

predicted, Drax power station

\section{Rating of cables buried in surface troughs}

The output from the model can be used to provide the ambient temperature parameter allowing the calculation of the surface temperature of cables buried in surface troughs. At present the ratings of buried cables are determined using a method based on Electra $87[10]$ and this is not ideally suited to surface trough installations. This can be resolved by using a conservative value of the ambient temperature 
parameter to account for the effect of changing weather conditions and a nonisothermal ground surface. A comparison of the two methods of specifying the ambient temperature parameter using data from the simulated cable trough has been undertaken. Using the model, the ambient soil temperature was calculated for $\mathbf{3 0}$ minute intervals and the cable rise above ambient was also calculated for 30 minute intervals using a method based on Electra 87 . The two values obtained at each sample instant were summed to produce a predicted cable surface temperature. This has been compared with the measured simulated cable surface temperature along with the estimated temperature using a conservative value of ambient temperature and a model based on Electra 87 (Figs. 7 and 8). The obtained results indicate a significant improvement when using the proposed model over the present approach. The test section of surface trough was programmed to simulate continuous and cyclic loads over a 24 -month period. The average error between the measured cable temperature and that obtained using the model to predict the ambient temperature parameter along with the average programmed cable loss $\left(\mathrm{Wm}^{-1}\right)$ are detailed in Table 2.

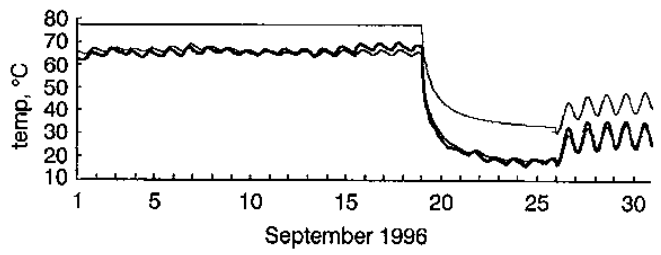

Fig.7 Comparison of predicted and measured simulated cable surface temperature for September 1996 for contimuous load (September 1-19)

- predicted using model

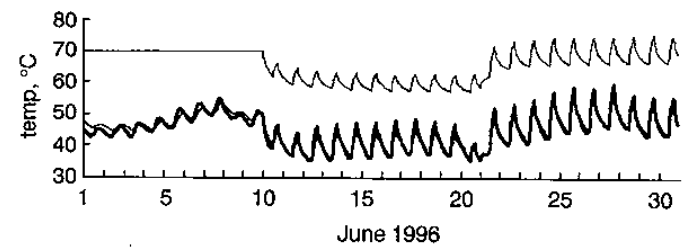

Fig.8 Comparison of predicted and measured simulated cable surface tem perature for June 1996 for cyclic load (June 10-30)

predicted using model

_ - predicted using standard

\section{Conclusions}

A model based on physical laws has been proposed that can predict the ambient temperature parameter required for determining the rating of cables buried in surface troughs. Results obtained indicate that the model offers a significant improvement on the existing approaches for determining the ambient temperature parameter. Using a fully instrumented test section of cable trough that was simulating continuous and cyclic loads, the model improved the accuracy of the rating calculation to within $2 \mathrm{~K}$ of the actual simulated cable temperature. The application of the results
Table 2: Average cable temperature error with model used to predict ambient temperature parameter

\begin{tabular}{|c|c|c|c|}
\hline Month & $\begin{array}{l}\text { Mean daily } \\
\text { maximum air } \\
\text { temperature } \\
\left({ }^{\circ} \mathrm{C}\right)\end{array}$ & $\begin{array}{l}\text { Average pre- } \\
\text { programmed } \\
\text { cable losses } \\
(\mathrm{Wm}-1)\end{array}$ & $\begin{array}{l}\text { Average error } \\
\text { in cable temp. } \\
\text { using model } \\
\text { to calculate } \\
\text { ambient temp. } \\
\text { parameter }\left({ }^{\circ} \mathrm{C}\right)\end{array}$ \\
\hline August 1995 & 26.6 & 28.9 & 0.2 \\
\hline September 1995 & 18.1 & 40.0 & 2.4 \\
\hline October 1995 & 18.0 & 26.2 & 1.4 \\
\hline November 1995 & 12.1 & 30.4 & 2.1 \\
\hline December 1995 & 6.6 & 32.9 & 2.1 \\
\hline January 1996 & 8.2 & 32.9 & 1.3 \\
\hline February 1996 & 6.8 & 38.6 & 1.1 \\
\hline March 1996 & 8.7 & 38.5 & 0.7 \\
\hline April 1996 & 13.4 & 41.3 & 0.3 \\
\hline May 1996 & 14.0 & 33.0 & 0.1 \\
\hline June 1996 & 20.4 & 43.1 & -0.1 \\
\hline July 1996 & 21.9 & 61.9 & -0.1 \\
\hline August 1996 & 21.4 & 80.0 & 2.7 \\
\hline September 1996 & 18.6 & 52.2 & 0.2 \\
\hline
\end{tabular}

obtained using the model for cable rating will require careful consideration. By increasing the accuracy of the soil ambient temperature parameter within the cable rating calculation the inherent safety margin provided by established ratings procedures would be significantly reduced.

\section{Acknowledgements}

The support of The National Grid Company plc in funding this work is gratefully acknowledged.

\section{References}

1 THEED, J.E., LEWIN, P.L., DAVIES, A.E., and LARSEN, S.T.: 'A study into the variability of environmental parameters used in cable ratings'. Proceedings of IEE international conference on $A C$ and $D C$ power transmission, 1996, pp. $64-69$

2 'Calculation of the continuous current rating of cables (100\% load factor)'. IEC 287 (1982)

3 THELWELL, M.J., and HITCHCOCK, J.A.: 'The evaluation of natural and forced cooled ratings of EHV cables using computational and analogue techniques'. Proceedings of IEE conference on Progress in overhead lines and cables for $220 \mathrm{kV}$ and above, 1968, pp. 323-331

4 WEEDY, B.M.: 'Thermal assessment of surface troughs for $400 \mathrm{kV}$ cables with air, backfill and water fillings', Electr. Power Syst. Res., 1989,16 , pp. 53-61

5 RAMDAS, L.A.: "Phenomena controlling the thermal balance at the ground surface'. Proceedings of UNESCO symposium on Climatology and microclimatology, Canberra, 1958, (UNESCO), pp. 129-133

6 MARKVART, T. (Ed): 'Solar electricity' (Wiley, 1994)

7 RAMDAS, L.A.: 'Some new instruments and experimental techniques developed in the Agricultural Meteorogy Section at Poona', J. Sci. Ind. Res., 1948, 7, (1), pp. 16-29

8 SWINBANK, W.C.: 'Long-wave radiation from clear skies', $Q . J$ Royal Meteorol. Soc., 1963, 89, pp. 339-348

9 DINES, W.H., and DINES, L.H.G.: 'Monthly mean values of radiation from various parts of the sky at Benson, Oxfordshire', Mem. Royal Meteorol. Soc., 1927, 2, (11), pp. $1-9$

10 CIGRE Committee 21, "Computer method for the calculation of the response of single core cables to a step function thermal transient'. 1983, Electra, 87 , pp $41-63$ 